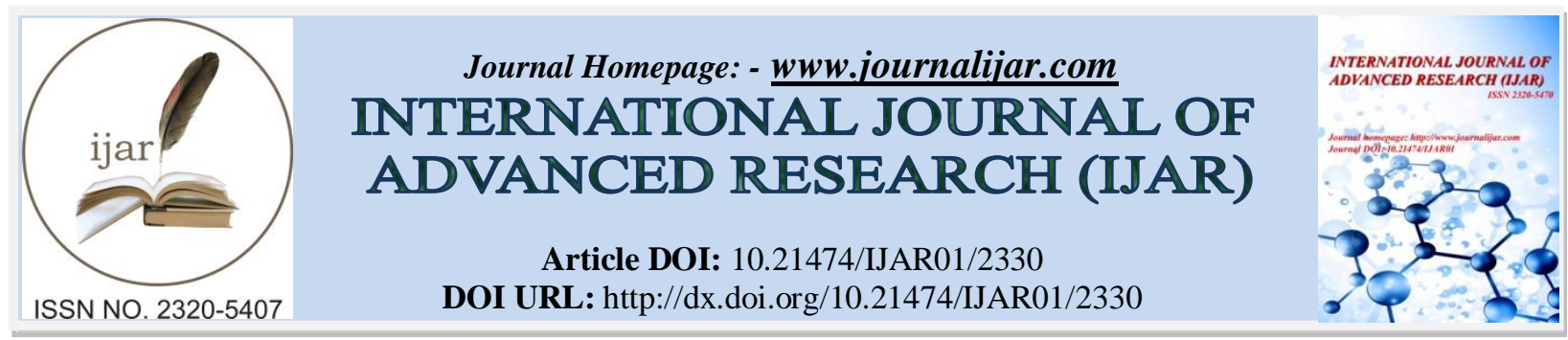

RESEARCH ARTICLE

\title{
LIFE STYLE RISK FACTORS PREDISPOSITION AND BLOOD LEVELS OF TRACE ELEMENTS AND HEAVY METALS AMONG FEMALE MEDICAL STUDENTS.
}

\section{Rana Hasanato ${ }^{1}$, SawsanSaad Bakry ${ }^{2},{ }^{*}$ Dina Khaled Assiri ${ }^{2}$, FelwaAbdulazizAIMarshad ${ }^{2}$, Nory Abdullah AlDosari $^{2}$, DeemaEssamJomar ${ }^{2}$ and Layla Mohammed Zeitouni ${ }^{2}$.}

1. Department of Pathology and Laboratory Medicine, College of Medicine King Saud University and King Saud University Medical City, Riyadh, Saudi Arabia.

2. College of Medicine, King Saud University.

\section{Manuscript Info}

[.........................

Manuscript History

Received: 30 September 2016

Final Accepted: 30 October 2016

Published: November 2016

Key words:-

Trace elements, Toxic, Lead, Arsenic, Copper

\section{Abstract}

Background: Repeated exposure to both essential and toxic elements can lead to bioaccumulation and toxicity of these elements.

Objectives: To assess the life style predisposing factors and the levels of both essential elements (zinc, copper and selenium) and heavy metals (mercury, lead, cadmium and arsenic) among healthy female medical students.

Methodology: This was a cross sectional study of 224 healthy female medical students (mean age $22.17 \pm 1.90$ years) performed between December 2013 and April 2014 at King Saud University. Information about exposure to risk factors was obtained using self-administered questionnaire. Blood levels of trace and toxic elements were assessed by Inductively Coupled Plasma Mass Spectrometry (ICPMS)and results were compared with normal reference ranges of Mayo Clinic.

Results: The mean serum level of trace elements including copper $(15.64 \pm 3.15) \quad \mu \mathrm{mol} / \mathrm{l}, \quad$ zinc $(11.43 \pm 1.60 \mu \mathrm{mol} / \mathrm{l})$ and selenium $(1.44 \pm 0.17 \mu \mathrm{mol} / \mathrm{l})$ were within the expected range. Similarly among the metals mean arsenic $(0.04 \pm 0.06 \mu \mathrm{mol} / \mathrm{l})$, mercury $(2.82 \pm 1.19$ $\mathrm{nmol} / \mathrm{l})$, lead $(0.25 \pm 0.16 \mu \mathrm{mol} / \mathrm{l})$ and cadmium $(16.93 \pm 10.23 \mathrm{nmol} / \mathrm{l})$ levels were also within the expected normal ranges. Eyeliner was used by $85.7 \%$, lip-gloss was used by $70.5 \%, 72.8 \%$ consumed canned food and $71 \%$ consumed sea food regularly. Only $6.25 \%$ were smokers. Serum lead levels in $24(10.7 \%)$ and arsenic levels in 11 (5\%) students were higher than the expected normal values. None of the risk factors was found to be a significant predisposition.

Conclusion: Despite of the exposure to predisposing factors the female medical students had normal mean blood levels of trace elementsand heavy metals.

Copy Right, IJAR, 2016,. All rights reserved.

\section{Introduction:-}

Alterations in trace elements particularly their deficiency can adversely affect health outcomes such as the immune status, growth cognitive functions and physical development(Viteriand Gonzalez, 2002). Zinc is an essential trace element among humans and its deficiency is frequently observed among elderly and patients receiving totalparenteral nutrition devoid ofzinc supplementation (Plum et al., 2010). Low serum levels of trace elements 
including zinc have been linked with increased oxidative stress and immune dysfunction (Guo et al., 2011a). Little is known about copper and zinc homeostasis but it is evident that increased copper/zinc ratio is associated with inflammation, increased oxidative stress, nutritional and immune abnormalities (Guo et al., 2011b). Moreover selenium found in sea food has also been shown to be a vital component of anti-oxidant enzymes and is critical for handling increased oxidative stress (Yamashita et al., 2013). Although short term recognition of trace element deficiencies appears to be difficult long term monitoring of micronutrient status however appears to be crucial for maintenance of normal health.

Environmental exposure to heavy metal ions is diverse due to their wide distribution. Exposure to lead may occur through respiratory tract by inhalation, gastrointestinal tract by consumption of foods containing lead or as an occupational hazard (Gillis et al., 2012). Compared to the males the female gender has been shown to have higher blood lead levels most likely due to a higher exposure to predisposing factors (Zolaly et al., 2011). Cigarettesmokers tend to have higher blood levels of lead and cadmium thus a predisposing these individuals to increased risk of having peripheral vascular disease (Navas-Acien et al., 2004).A study investigating the effect of passive smoking has revealed that children residing with cigarette smokers have higher blood lead levels than those living in nonsmoking households (Al-Nozha et al., 2009).Moreover increased dietary intake of cadmium among postmenopausal women has been shown to exhibit a strong association with development of breast cancer (Julin et al., 2012).A higher exposure to mercury can result in bioaccumulation of the metal ions and is associated with significant morbidity and mortality. Consumption of certain fish and wheat grains, use of skin lightening creams, inhalation of paints and having amalgam fillings in teeth have been associated with high levels of mercury in blood (Azevedo et al., 2012; Peregrino et al., 2011; Saatchi et al., 2013).This study was performed to assess blood levels of trace elements and metal ions among otherwise healthy female medical students at the College of Medicine, King Saud University, Riyadh.

\section{Methods:-}

This quantitative, observational cross-sectional study was performed at King Khalid University Hospital, Riyadh between December 2013 and April 2014. A questionnaire specifically designed for the study was handed over to 300 students of the College of Medicine and out of the total 224students responded. The mean age of this group of otherwise healthy female medical students was $22.17 \pm 1.9$ years (range 18-28 years). Participants suffering from chronic disorders such as diabetes mellitus, hypertension, asthma or autoimmune disease were excluded from the study. The questionnaire included queries on different life-style habits such as cigarette smoking, use of eyeliner, lip-gloss, hair dyes, skin lightening creams, tooth amalgam fillings, exposure to paint, sea food and canned food consumption. After obtaining the informed consent of each participant six milliliters of venous blood sample was drawn from anti-cubital fossa. Three milliliters of the blood sample was dispensed in an acid washed royal blue tube containing tripotassium-ethylene diamine tetra acetic acid (EDTA) for assessment of arsenic, lead, cadmium and mercury and the remaining $3 \mathrm{ml}$ of the sample was dispensed in an acid washed royal blue tube for estimation of copper, selenium and zinc. The blood levels of all the trace elements and heavy metal ions were assessed by Inductively Coupled Plasma Mass Spectrometry (ICP-MS)technology (Thermo Scientific XSERIES 2 ICPMS).Because of the lacking normal reference ranges for trace elements and heavy metal ions of the local population Mayo clinic reference ranges were used to interpret the data. This study was approved by the Institutional Review Board of the College of Medicine, King Saud University, Riyadh.

\section{Statistical Analysis:-}

Data wereanalyzed using SPSS version 20 (SPSS, IBM Corporation, Armonk, New York, USA). Descriptive statistics such as mean and standard deviation (SD) were used to describe study variables. Chi-square test was used to test associations and cross tabulation was performed to obtain the odds ratios (OR) with $95 \%$ confidence interval (CI) to test the strength of the association between toxic elements with various risk factors. A $p \leq 0.05$ was considered statistically significant.

\section{Results:-}

Out of 300 students 224 participants completed the questionnaire with a response rate of $74.6 \%$. Table 1 describes data for blood levelsof the trace elements and heavy metal ions. The mean blood level of copper was $15.64 \pm 3.15$ $\mu \mathrm{mol} / \mathrm{l}$, zinc $11.43 \pm 1.60 \mu \mathrm{mol} / \mathrm{l}$ and selenium was $1.44 \pm 0.17 \mu \mathrm{mol} / \mathrm{l}$ whereas the mean blood level of metal ions such as arsenic was $0.04 \pm 0.06 \mu \mathrm{mol} / \mathrm{l}$, mercury was $2.82 \pm 1.19 \mathrm{nmol} / \mathrm{l}$, lead was $0.25 \pm 0.16 \mu \mathrm{mol} / \mathrm{l}$ and cadmium was $16.93 \pm 10.23 \mathrm{nmol} / \mathrm{l}$. The mean blood levels of the trace elements and heavy metal ions were within expected normal 
range. Figure 1 shows data for predisposing factors among 224 female medical students included in the study. The use of eyeliner was observed most frequently where $192(89.7 \%)$ students were using eyeliner on regular basis this was followed by canned food consumption by $163(72.8 \%)$, seafood consumption by 159 (71\%), lip gloss use by 158 (70.5\%), house paint exposure by $59(26.3 \%)$ students. Among the group $14(6.25 \%)$ students were smokers. Lead was found to be higher than the reference range in $24(10.7 \%)$, arsenic in $11(4.9 \%)$ and cadmium was high in 2 $(0.9 \%)$ students (Fig. 2). Blood levels of zinc, copper and selenium were within normal reference range among all the female students include in the study. None of the predisposing factors included in the questionnaire was found to be a significant risk factor (Table. 2)

\section{Discussion:-}

Whereas the blood levels of essential trace elements were within acceptable range alterations in heavy metals were observed despite normal mean concentrations. A sizable proportion of healthy female students $(10.7 \%)$ had high blood levels of lead.High blood levels of lead up to $14 \%$ of adults were recently reported from Nigeria among healthy individuals residing in vicinity of lead-zinc mines most likely due to lead exposure through drinking water (Bello et al., 2016). Lead can be easily transferred through placenta and blood brain barrier (Caserta et al., 2013). Prenatal exposure to lead has been linked with adverse pregnancy outcomes such as fetal loss (Borja-Aburto et al., 1999), retarded fetal growth (Hernandez-Avila et al., 2002) congenital anomalies (Jin et al., 2013) and impaired neurodevelopment (Sanders et al., 2009).Higher lead concentration in blood particularly among the female population is not only harmful for the individual but is also a significant risk factor for the off-spring.Elevated lead levels among healthy female students observed in the present study therefore emphasizes the need for continuous monitoring of blood levels of lead and avoidance of lead exposure.

The presence of lifestyle risk factors appears to have a direct bearing on blood levels of heavy metals. Residing in areas with higher number of lead industriesis a risk factor for having higher blood lead levels (de Almeida Lopes et al., 2015). Fried clay traditionally used for the treatment of gastritis during pregnancy in Congo has been linked with higher blood lead levels in the off-springs (Tuakuila et al., 2013).Among the female gender the frequent use of lead containing cosmetics is considered as an important source of exposure to lead.High lead content of eyeliners and their frequent use has been shown to be associated with high blood lead levels (Parry and Eaton, 1991).Similarly "tiro" a lead containing Nigerian cosmetic is applied on the eyelids of children as a folk remedy for promotion of visual development has been associated with elevated blood lead levels (Centers for Disease Control and Prevention, 2012). Moreover the use of lip gloss among females has also been implicated in high blood lead levels (Zolaly et al., 2012). Eyeliner was used by the majority of the students in this study andnone of the life style risk factors including the use of lead containing cosmetics investigated in the present study was associated with high blood lead levels.

Elevated blood levels of arsenic were found in $4.9 \%$ of the healthy female students in this study though none of the predisposing factors posed a significant risk. Seafood consumption is believed to be a major source of arsenic exposure (Borak and Hosgood, 2007). Low-level exposure to arsenic has been associated with a greater risk of having pre-malignant skin lesions (Chen et al., 2009), hypertension (Jones et al., 2011) and neurological dysfunction (Mukherjee et al., 2003). Among the female gender exposure to arsenic during pregnancy correlates with low birth weight by decreasing the gestational age of the offspring (Kile et al., 2016). The detection of high blood levels of arsenic in healthy female students appears to be a major concern not only due to associated toxic effects on the individual but as potential mothers to their off-springs as well.In addition measures should also be implemented for cutting down the exposure to arsenic by detections of possible sources of exposure.

Food safety is a major health concern all over the world because food consumption is considered as the main source of exposure to toxic elements (Liu et al., 2013).Heavy metals such as lead, zinc, copper and cadmium have been detected in eggs and dairy products (Shang and Wang 1997; Abdulkhaliq et al., 2012). Considerably higher amounts of lead, zinc and copper present in preserved eggs poses a significant risk of exposure to the consumers (Fu et al., 2014). Vegetables are also potential sources of exposure to lead, cadmium, mercury and arsenic particularly when cultivated in soil contaminated with higher concentrations of these heavy metals (Liu et al., 2013).Food preservation in cans and the type of materials used in can manufacturing may also contribute to accumulation of lead in the preserved foods (Kassouf et al., 2013). The association of fish consumption over one meal per week and elevated mercury content of the hair is considered as a self-protection response by mitigating blood mercury levels in the event of higher exposure to mercury (Vieira et al., 2015).This observation emphasizes the need for concomitant assessment of heavy metals particularly mercury in nails and hair samples along with blood levels. Although none of the risk factors investigated posed a significant risk periodic bio-monitoring of trace elements and heavy metals among healthy population may be a useful tool for early detection and avoidance of heavy metal toxicity. 
In conclusion among the female students the lifestyle risk factors did not pose any risk for having significantly high blood levels of trace elements or heavy metals. The detection of higher than acceptable blood levels of lead and arsenic in a sizable proportion of normal healthy females prompts continuous bio-monitoring trace elements and heavy metals. Attempts should be made for identifying the possible sources of exposure and avoidance of environmental exposure. The study was limited by relatively small number of participants and large scale studies are recommended for concurrent assessment of trace elements and heavy metals in hair and nail samples along with the blood.

Table 1:- Assessment of blood levels of trace elements and heavy metals among 224 healthy female medical

\begin{tabular}{|l|l|l|}
\hline \multicolumn{3}{|c|}{ students. } \\
\hline Element & Mean \pm sd & Normal Range* \\
\hline Copper & $15.06 \pm 3.15 \mu \mathrm{mol} / 1$ & $13-24 \mu \mathrm{mol} / 1$ \\
\hline Zinc & $11.43 \pm 1.60 \mu \mathrm{mol} / 1$ & $11-19 \mu \mathrm{mol} / 1$ \\
\hline Selenium & $1.44 \pm 0.17 \mu \mathrm{mol} / 1$ & $0.88-1.9 \mu \mathrm{mol} / 1$ \\
\hline Arsenic & $0.04 \pm 0.06 \mu \mathrm{mol} / 1$ & $<0.16 \mu \mathrm{mol} / 1$ \\
\hline Mercury & $2.81 \pm 1.19 \mathrm{nmol} / 1$ & $<45.0 \mathrm{nmol} / 1$ \\
\hline Lead & $0.25 \pm 0.16 \mu \mathrm{mol} / 1$ & $<0.4 \mu \mathrm{mol} / 1$ \\
\hline Cadmium & $16.93 \pm 10.23 \mathrm{nmol} / 1$ & $<50.0 \mathrm{nmol} / 1$ \\
\hline
\end{tabular}

*Mayoclinic reference range for adults $\mathrm{sd}=$ standard deviation

Table 2:- Life style risk factors predisposition and blood levels of trace elements and heavy metals among 224

\begin{tabular}{|c|c|c|c|c|c|}
\hline Exposure & HBLL* & NBLL** & $\mathrm{OR}^{* * *}$ & $\begin{array}{l}95 \% \\
\text { CI } \\
\end{array}$ & $\begin{array}{l}P \\
\text { Value }\end{array}$ \\
\hline \multicolumn{6}{|c|}{ Staying at a recently built house } \\
\hline Yes & 2 & 34 & \multirow[t]{2}{*}{0.44} & $0.10-$ & \multirow[t]{2}{*}{0.384} \\
\hline No & 22 & 166 & & 1.98 & \\
\hline \multicolumn{6}{|c|}{ Exposure to house paint } \\
\hline Yes & 3 & 56 & \multirow[t]{2}{*}{0.37} & $0.10-$ & \multirow[t]{2}{*}{0.141} \\
\hline No & 21 & 144 & & 1.28 & \\
\hline \multicolumn{6}{|c|}{ Use of eyeliner } \\
\hline Yes & 17 & 175 & \multirow[t]{2}{*}{0.35} & $0.13-$ & \multirow[t]{2}{*}{0.066} \\
\hline No & 7 & 25 & & 0.92 & \\
\hline \multicolumn{6}{|c|}{ Use of lip-gloss } \\
\hline Yes & 17 & 141 & \multirow[t]{2}{*}{1.02} & $0.40-$ & \multirow[t]{2}{*}{0.942} \\
\hline No & 7 & 59 & & 2.58 & \\
\hline \multicolumn{6}{|c|}{ Use of hair dye } \\
\hline Yes & 6 & 50 & \multirow[t]{2}{*}{1.00} & $0.38-$ & \multirow[t]{2}{*}{0.941} \\
\hline No & 18 & 150 & & 2.66 & \\
\hline \multicolumn{6}{|c|}{ Consuming canned food } \\
\hline Yes & 14 & 149 & \multirow[t]{2}{*}{0.48} & $0.20-$ & \multirow[t]{2}{*}{0.236} \\
\hline No & 10 & 51 & & 1.15 & \\
\hline \multicolumn{6}{|c|}{ Tobacco use } \\
\hline Yes & 2 & 12 & \multirow[t]{2}{*}{1.42} & $0.30-$ & \multirow[t]{2}{*}{1.000} \\
\hline No & 22 & 188 & & 6.78 & \\
\hline
\end{tabular}

*High blood lead levels

**Normal blood lead levels

***Odds Ratio (OR) with $95 \%$ confidence interval (CI) 


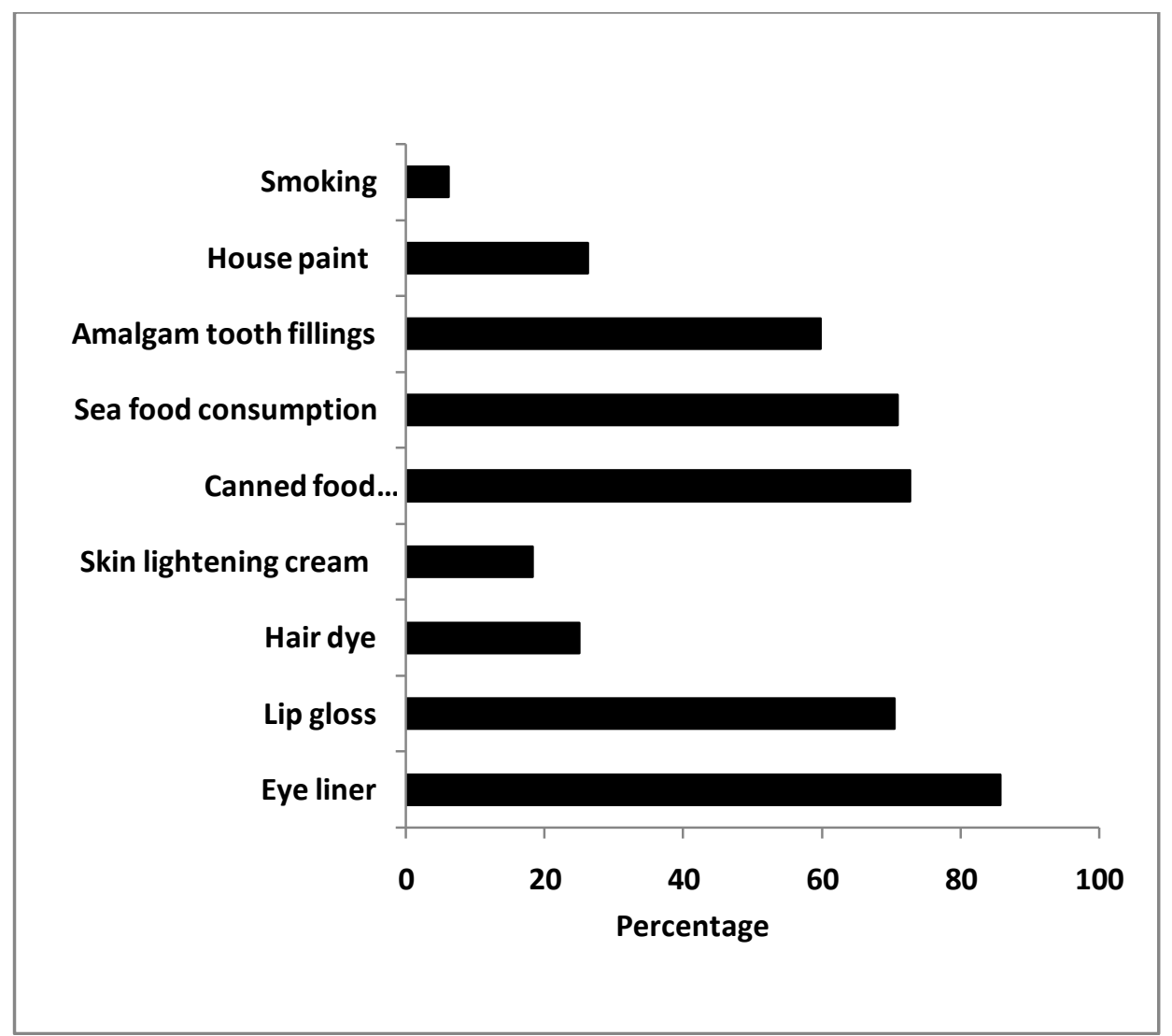

Fig. 1:- Life style predisposing factors among 224 female medical students.

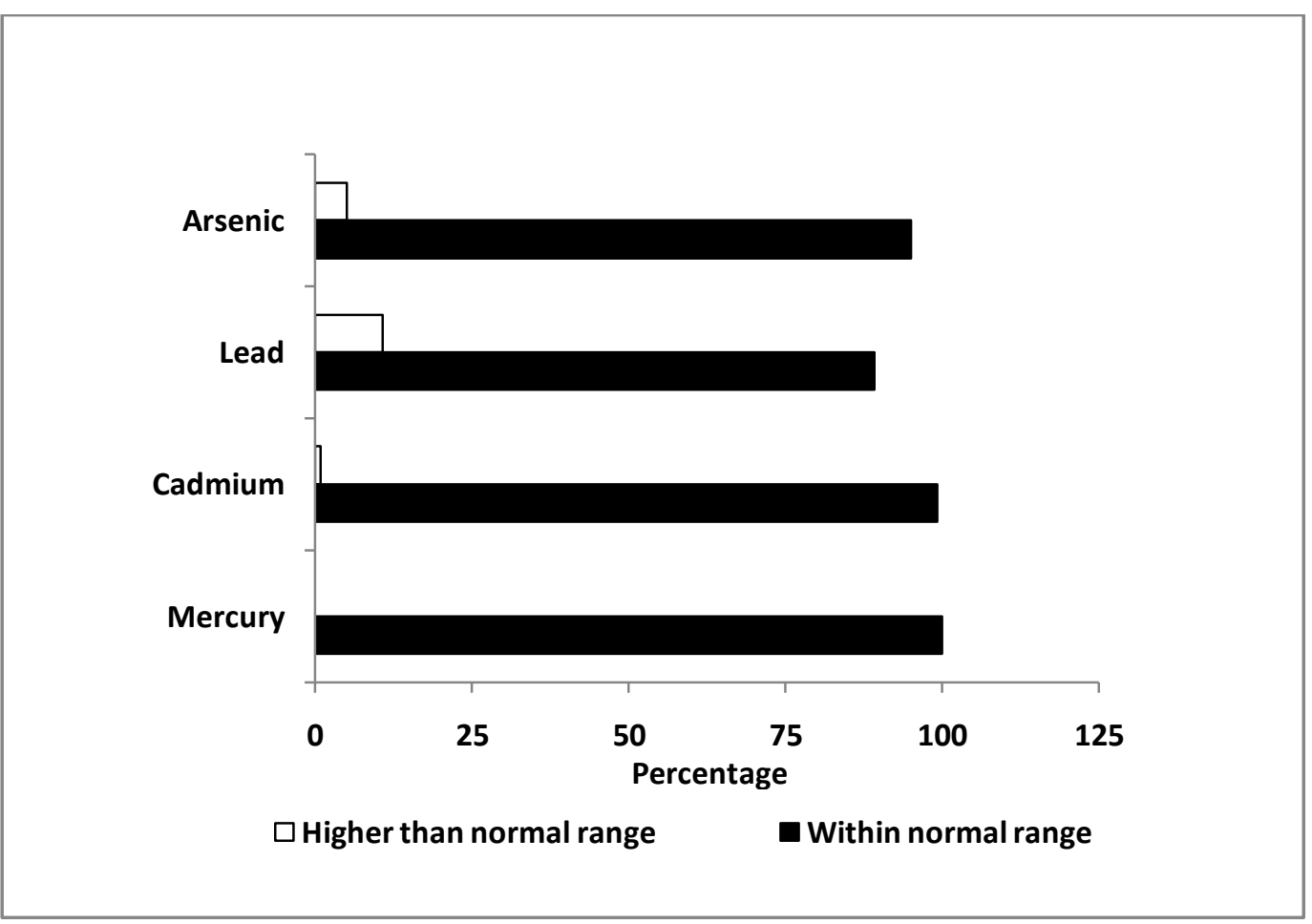

Fig. 2:- Assessment of blood levels of heavy metals among 224 female medical students 


\section{References:-}

1. Abdulkhaliq, A., Swaileh, K., Hussein, R. andMatani, M. (2012). Levels of metals (Cd, $\mathrm{Pb}, \mathrm{Cu}$ and $\mathrm{Fe}$ ) in cow's milk, dairy products and hen's eggs from the West Bank, Palestine. Int. Food Res. J., 19:1089-1094.

2. Al-Nozha, M., Al-Mazrou, Y., Arafah, M., Al-Maatouq, M., Khalil, M., Khan, N. Al-Khadra, A., Al-Marzouki, K., Al-Harthi, S.S., Abdullah, M., Al-Shahid, M.S., Al-Mobeireek, A. and Nouh, M.S. (2009): Smoking in Saudi Arabia and its relation to coronary artery disease. J. Saudi Heart Assoc., 21(3):169-176.

3. Bello, O., Naidu, R., Rahman, M.M., Liu, Y. and Dong, Z. (2016): Lead concentration in the blood of the general population living near a lead-zinc mine site, Nigeria: Exposure pathways. Sci. Total Environ., 15;542(Pt A):908-14.

4. Borak, J. andHosgood, H.D. (2007): Seafood arsenic: implications for human risk assessment. Regul.Toxicol.Pharmacol.,47(2):204-12.

5. Borja-Aburto, V.H., Hertz-Picciotto, I., Rojas Lopez, M., Farias, P., Rios, C. and Blanco, J. (1999): Blood lead levels measured prospectively and risk of spontaneous abortion. Am. J. Epidemiol., 150:590-597.

6. Azevedo, B.F.,Furieri, L.B., Peçanha, F.M.,Wiggers, G.A., Vassallo, P.F. Simões, M.R.,Fiorim, J., de Batista, P.R.,Fioresi, M., Rossoni, L., Stefanon, I. Alonso, M.J., Salaices, M. and Vassallo, DV.(2012). Toxic effects of mercury on the cardiovascular and central nervous systems. J. Biomed.Biotechnol., 2012: 949048.

7. Caserta, D., Graziano, A., Lo Monte, G., Bordi, G. andMoscarini, M. (2013): Heavy metals and placental fetalmaternal barrier: A mini-review on the major concerns. Eur. Rev. Med. Pharmacol. Sci.,17:2198-2206.

8. Centers for Disease Control and Prevention (CDC). (2012): Infant lead poisoning associated with use of tiro, an eye cosmetic from Nigeria--Boston, Massachusetts, 2011. MMWR Morb. Mortal. Wkly. Rep., 61(30):574-576.

9. Chen, Y., Parvez, F., Gamble, M., Islam, T., Ahmed, A., Argos, M., et al. (2009): Arsenic exposure at low-tomoderate levels and skin lesions, arsenic metabolism, neurological functions, and biomarkers for respiratory and cardiovascular diseases: review of recent findings from the Health Effects of Arsenic Longitudinal Study (HEALS) in Bangladesh. Toxicol. Appl.Pharmacol., 239(2):184-92

10. de Almeida Lopes, A.C., Navas-Acien, A., Zamoiski, R., Silbergeld, E.K., CarvalhoMde, F., Buzzo, M.L., Urbano, M.R., Martins Ada, C. Jr. andPaoliello, M.M. (2015). Risk factors for lead exposure in adult population in southern Brazil. J.Toxicol. Environ. Health A..78(2):92-108.

11. Fu, Q.L., Liu, Y., Li, L. and Achal V. (2014): A survey on the heavy metal contents in Chinese traditional egg products and their potential health risk assessment. Food Addit.Contam. Part B Surveill., 7(2):99-105.

12. Gillis, B., Arbieva, Z. and Gavin, I. (2012): Analysis of lead toxicity in human cells. BMC genomics.,13(1):344.

13. Guo, C.H., Chen, P.C., Yeh, M.S., Hsiung, D.Y. and Wang, C.L. (2014): Cu/Zn ratios are associated with nutritional status, oxidative stress, inflammation and immune abnormalities in patients on peritoneal dialysis. Clin.Biochem., 44: 275-280b.

14. Guo, C.H., Wang, C.L., Chen, P.C. and Yang TC. (2011): Linkage of some trace elements, peripheral blood lymphocytes, inflammation, and oxidative stress in patients undergoing either hemodialysis or peritoneal dialysis. Perit. Dial. Int., 31: 583-591a.

15. Hernandez-Avila, M., Peterson, K.E., Gonzalez-Cossio, T., Sanin, L., Aro, A., Schnaas, L. and Hu, H. Effect of maternal bone lead on length and head circumference of newborns and 1-month-old infants. Arch. Environ. Health. 57:482-488.

16. Jin, L., Zhang, L., Li, Z., Liu, J.M., Ye, R. and Ren A. (2013): Placental concentrations of mercury, lead, cadmium, and arsenic and the risk of neural tube defects in a chinese population. Reprod. Toxicol. 35:25-31.

17. Jones, M.R., Tellez-Plaza, M., Sharrett, A.R., Guallar, E. andNavas-Acien, A. (2011): Urine arsenic and hypertension in US adults: the 2003-2008 National Health and Nutrition Examination Survey. Epidemiol.,22(2):153-61.

18. Julin, B., Wolk, A., Bergkvist, L., Bottai,M. andAkesson A. (2012). Dietary cadmium exposure and risk of postmenopausal breast cancer: a population-based prospective cohort study. Cancer res., 72(6):1459-1466.

19. Kassouf, A., Chebib, H., Lebbos, N. andOuaini, R. (2013): Migration of iron, lead, cadmium and tin from tinplate-coated cans into chickpeas. Food AdditContam Part A Chem. Anal Control Expo. Risk Assess.,30(11):1987-92.

20. Kile, M.L., Cardenas, A., Rodrigues, E., Mazumdar, M., Dobson, C., Golam, M., Quamruzzaman, Q., Rahman, M. andChristiani, D.C. (2016): Estimating effects of arsenic exposure during pregnancy on perinatal outcomes in a Bangladeshi cohort. Epidemiol.,27(2): 173-181.

21. Liu, W., Song, Q., Tang, Y., Li, W., Xu, J., Wu, J., Wang, F. andBrokes PH. Human health risk assessment of heavy metals in soil-vegetable system: a multi-medium analysis. Sci. Total Environ., 463-464:530-540

22. Liu, X., Song, Q., Tang, Y., Li, W., Xu, J., Wu, J., Wang, F. and Brookes, P.C. (2013): Human health risk 
assessment of heavy metals in soil-vegetable system: a multi-medium analysis. Sci. Total Environ., 463464:530-40.

23. Mukherjee, S.C., Rahman, M.M., Chowdhury, U.K., et al. (2003): Neuropathy in arsenic toxicity from groundwater arsenic contamination in West Bengal, India. J. Environ. Sci. Health A Tox. Hazard Subst. Environ. Eng. 38 (1):165-83.

24. Navas-Acien, A., Selvin, E., Sharrett, A., Calderon-Ar, E, Silbergeld, E., et al. Lead, cadmium, smoking, and increased risk of peripheral arterial disease. Circulation., 109(25):3196-3201.

25. Parry, C. and Eaton, J. (1991): Kohl: a lead-hazardous eye makeup from the Third World to the First World. Environ. Health Perspect. 94:121.

26. Peregrino, C.P., Moreno, M.V., Miranda, S.V., Rubio, A.D. and Leal, L.O. (2011): Mercury levels in locally manufactured Mexican skin-lightening creams. Int.J. Envi. Res.Pub.health., 8(6):2516--2523.

27. Plum, L., Rink, L. andHaase, H. (2010): The essential toxin: impact of zinc on human health. Int.J. Envi. Res. Pub.health.,7(4):1342--1365.

28. Saatchi, M., Shadmehr, E., Talebi, S. andNazeri, M. (2013): A Prospective Clinical Study on Blood Mercury Levels Following Endodontic Root-end Surgery with Amalgam. Iran.Endodontic J., 8(3):85.

29. Sanders, T., Liu, Y., Buchner, V. andTchounwou, P.B. (2009):Neurotoxic effects and biomarkers of lead exposure: A review. Rev. Environ. Health., 24:15-45.

30. Shang, S. and Wang, H. (1997): Flame atomic absorption spectrometric determination of copper, zinc, calcium, magnesium and iron in fresh eggs using microvolume injection. Talanta., 44:269-274.

31. Tuakuila, J., Lison, D., Mbuyi, F., Haufroid, V. and Hoet, P. (2013): Elevated blood lead levels and sources of exposure in the population of Kinshasa, the capital of the Democratic Republic of Congo. J. Expo. Sci. Environ.Epidemiol., 23(1):81-7.

32. Vieira, H.C., Morgado, F., Soares, A.M. and Abreu, S.N. (2015): Real and potential mercury accumulation in human scalp of adolescents: a case study. Biol. Trace Elem. Res., 63(1-2):19-27.

33. Viteri, F.E. and Gonzalez, H. (2002): Adverse outcomes of poor micronutrient in childhood and adolescence. Nutr. Rev., 60:S77-83.

34. Yamashita, Y., Yamashita, M. and Iida, H. (2013): Selenium Content in Seafood in Japan. Nutrients., 5(2):388-395.

35. Zolaly, M., Hanafi, M., Shawky, N., El-Harbi, K. andMohamadin, A. (2011): Association between blood lead levels and environmental exposure among Saudi schoolchildren in certain districts of Al-Madinah. Int.J.Gen. Med., 5:355-364.

36. Zolaly, M.A., Hanafi, M.I., Shawky, N., El-Harbi, K., Ahmed, M. andMohamadin, A.M. (2012): Association between blood lead levels and environmental exposure among Saudi schoolchildren in certain districts of AlMadinah. Int. J. Gen. Med., 5: 355-364. 